\title{
Políticas educacionais e concepção de gestão: o que dizem os diretores de escolas de ensino médio do Distrito Federal
}

\section{Educational policies and administration conceptions: what say the high school principals of the Federal District}

\author{
Rodrigo da Silva Pereira* \\ Maria Abádia da Silva**
}

\begin{abstract}
RESUMO
Este artigo tem como objetivo analisar as concepções de gestão dos diretores de escolas públicas de ensino médio do Distrito Federal (DF). Para isso está organizado em três seções: a introdução que discute os marcos históricos do debate, a discussão sobre as disputas em torno da temática e, finalmente, os sentidos atribuídos pelos gestores aos elementos constitutivos da gestão escolar. Além disso se propõe a problematizar a descontinuidade legal de políticas para gestão democrática no âmbito do DF e analisar como esse movimento incide na fala e nas práticas no interior das instituições de ensino médio. Aponta que há certo hibridismo de concepções e que as práticas são desenvolvidas a partir de movimentos e apreensões contraditórias. Indica ainda que há espaço para o questionamento das políticas de caráter tecnoburocráticas a partir do fortalecimento dos órgãos colegiados e da reflexão crítica que possam aprofundar os mecanismos de participação, compromisso ético-político e engajamento profissional com vistas a uma formação emancipadora.
\end{abstract}

Palavras-chave: Políticas educacionais. Gestão escolar. Distrito Federal.

* Universidade Federal da Bahia. Faculdade de Educação. Salvador, Bahia, Brasil. E-mail: rodrigosilvapereira@ufba.br. https://orcid.org/0000-0003-0371-3789.

** Universidade de Brasília. Brasília, Distrito Federal, Brasil. E-mail: abadiaunb@gmail. com. https://orcid.org/0000-0001-8605-3805. 


\begin{abstract}
This article aims to analyze the administration conceptions of public school principals of the Federal District (DF) in Brazil. In order to accomplish this, it is organized in three sections: the introduction that discusses the historical highlights of the debate, the topic about the disputes around the theme and, finally, the meanings attributed by the principals to the constitutive elements of school administration. The work also problematizes the legal discontinuity of policies for democratic administration in the Federal District and analyzes how this movement affects speech and practices at secondary education schools. The results point out that there is a certain hybridism of conceptions and that the practices are developed from contradictory movements and apprehensions. They also indicate that there are conditions for the questioning of techno-bureaucratic policies by empowering school bureaus and reflecting critically, deepening mechanisms for participation, ethical-political commitment and professional engagement focused on emancipatory education.
\end{abstract}

Keywords: Educational Policies. School Administration. Federal District.

\title{
Introdução
}

Analisar as questões e concepções que permeiam o debate e as práticas acerca da gestão educacional e escolar pressupõe refletir sobre as determinações que incidem no cotidiano das relações dinâmicas e contraditórias entre o Estado, a sociedade e as políticas educacionais. Essa perspectiva leva em consideração que tais relações condicionam determinados tipos de gestão escolar que dependem dos contextos concretos em que se materializam. Nesse sentido, a pesquisa que amparou a construção deste trabalho buscou, na fala de diretores e diretoras escolares do ensino médio do Distrito Federal (DF), os elementos que subsidiaram a análise em tela.

Nosso objetivo consiste em problematizar as concepções de gestão escolar que são desenvolvidas e materializadas na rede pública do DF a fim de contribuir para a compreensão, a reflexão e a análise dos próprios sujeitos do fazer-escolar. Nossa intencionalidade é a ampliação do debate com vistas a fortalecer os mecanismos democráticos de gestão que estão consubstanciados no marco legal distrital e federal. Porém, não por um viés racional-legal, mas, sim, a partir das experiências concretas da realidade vivenciada pelos trabalhadores e trabalhadoras docentes que, eleitos democraticamente, exercem a direção escolar. 
Se é consistente o argumento que as práticas de gestão escolar adquirem materialidade em contextos determinados - portanto, diversos - e que essa condição dá ao cotidiano das escolas apropriações diferenciadas em cada uma das instituições, é prudente afirmar que os movimentos aludidos também são influenciados pelas políticas educacionais implementadas em âmbito local e nacional com aspectos globais que, por sua vez, emergem da relação que o Estado estabelece com diferenciados atores, sejam eles públicos e/ou privados.

Partindo dessa acepção, é forçoso analisar as concepções de gestão escolar preconizadas em âmbito internacional e que terão nos organismos internacionais seus próceres. Na América Latina, desde a década dos anos de 1990 até os dias atuais, organizações como a Comissão Econômica para a América Latina e o Caribe (CEPAL), influenciada pelo grupo Banco Mundial, e a Organização para a Cooperação e Desenvolvimento Econômico (OCDE) desenvolvem propostas que buscam padronizar métodos e técnicas de gestão escolar sob a perspectiva racional-burocrática de razão mercantil. Essas proposições são desenvolvidas no âmbito de processos mais amplos de redefinições do papel do Estado e da ascensão do neoliberalismo num contexto de reestruturação produtiva e globalização econômica.

Assim, tais determinações compõem a essência de políticas educacionais que induzem determinadas práticas de gestão escolar e vão influenciar o cotidiano da escola e do trabalho docente do(a) diretor(a). No início dos anos de 1990, a "utopia da globalização" (FIORI; TAVARES, 1998) forneceu as bases materiais e ideológicas da nova faceta liberal da burguesia no Estado. No Brasil, a fragilização institucional, diante do apoio externo e do comprometimento com a dívida crescente, foram argumentos utilizados para uma reforma do aparelho do Estado que abrangeu várias dimensões do sistema de ensino: avaliação, currículos, gestão educacional, legislação, planejamento, entre outras.

Numa nova visão em busca da racionalidade técnica, a reforma dos anos de 1990 impôs uma condição de superveniência à lógica de formação para o mercado e suas relações produtivas, cujo incentivo à inovação, aos contratos de gestão e ao desempenho vinculado à remuneração docente se sustentam na retórica de uma qualidade requerida à educação, que falida e desorganizada no discurso, se constituía incapaz de tornar o Estado brasileiro em um passageiro do desenvolvimento econômico.

Ademais, a nova gestão caracterizada a partir desse cenário estabelece um conjunto de determinantes que enfatizam a formação de intelectuais de novo tipo (MARTINS; NEVES, 2015) a fim de constituir "pessoas neoliberais" (BALL, 2014), que são alienadas do debate democrático e participativo presente nas discussões em torno da gestão da educação, especialmente, emanadas dos 
movimentos sociais de base e inseridos nos preceitos normativos da Constituição Federal de 1988 e da Lei de Diretrizes e Bases de 1996.

No caso brasileiro, a gestão da política pública educacional está compreendida como uma necessidade de reproduzir maior racionalidade à sua gestão, calcada em formas mais flexíveis e descentralizadoras da administração de recursos e da responsabilização dos atores. O momento tangente é o de estabelecimento dos preceitos da administração empresarial para a administração pública e para a gestão educacional, configurada nos preceitos da gestão gerencial de ethos privado.

Em que pese a influência dessa nova forma de gestão pública no campo da educação, há que se considerar que, "evidenciada no gerencialismo, também estimula a participação e o controle instrumental” (SILVA, 2003, p. 228), porém, propõe uma escola à luz de um padrão que seja eficaz, eficiente, útil, prático, produtivo e de alcance de metas que se distanciam da natureza formativa, cultural e humana na criação de conteúdo, bem como de valores democráticos e de justiça social (SILVA, 2003).

Nesse sentido, a compreensão da gestão escolar, empreendida com a reforma do Estado dos anos 1990, perpassa pelo entendimento da configuração pela qual passa a sociedade, não apenas em seus aspectos socioculturais, mas principalmente pelo novo formato advindo do slogan da sociedade do conhecimento, que no discurso de aproximação de fronteiras, estabeleceu uma nova hegemonia que pôs a caminho uma educação homogeneizada. A partir de então deixou de lado aspectos históricos de compreensão do homem para se utilizar de procedimentos técnico-racionais pondo a prova um tipo de transmissão de conhecimento distante do ato transformador e de função emancipatória da educação.

O debate sobre a gestão da educação decorre de duas grandes perspectivas ao longo dos anos, do modelo taylorista-fordista, à teoria do capital humano. No primeiro intento tem o pressuposto da teoria da administração tecnoburocrática e patrimonialista, alvissareiras da organização dura e fiel aos requisitos da centralidade. A segunda tem como pano de fundo o indivíduo competente e habilidoso para o enfrentamento dos desafios do cotidiano, cujo debate lento da democracia, da pluralidade e dos direitos sociais, deve ser transmutado pelo discurso da capacidade intrínseca do indivíduo, pelo conhecimento adquirido em tomar decisões e ser responsável pelo resultado coletivo.

Atualmente, a intensificação do trabalho do diretor nas escolas tem sido fruto de intensos debates, especialmente quando põe a gestão da educação como um dos mecanismos responsáveis pela multiplicidade de papel a ser desempenhado pelo diretor, muito menos se encaixa o pedagógico, e muito 
mais desvela o administrativo gerencial dentre sua função principal no contexto desse novo modelo da educação.

Nas últimas duas décadas, a gestão escolar do Distrito Federal sofreu impactos na forma de atuação de acordo com os governos distritais que se transpuseram entre 1995 a 2010. Mendes (2014) demonstra que tais sucessões governamentais (Cristovam Buarque - 1995/1998, Joaquim Roriz - 1999/2006 e José Arruda - 2007/2010) pautaram de forma incisiva alterações nas legislações que regulamentaram a gestão escolar, muito embora associadas às transformações sustentadas pelas reformas dos anos 1990. Pontuou que as normativas elencadas em boa parte seguiram interesses governamentais e não uma política de Estado, num cenário de fragilidades, descontinuidades, fragmentações, tensões e conflitos nas políticas educacionais.

Neste contexto, o presente artigo tem como objetivo identificar e analisar as concepções de gestão dos diretores de escolas públicas de ensino médio do Distrito Federal, principalmente as que se associam à contribuição de formular novas linhas de ações políticas no Distrito Federal.

Cabe destacar que o artigo é um recorte de uma pesquisa maior, desenvolvida pelo Grupo de Pesquisa sobre Organismos Internacionais, Política e Gestão da Educação (Águia). Tem como objetivo investigar e analisar a gestão de escolas de ensino médio regular do DF a partir dos seguintes eixos: perfil, formação, concepção de gestão, intensificação do trabalho e ética. Nesse artigo, o trabalho será de análise de apenas um dos eixos: concepção de gestão.

A gestão escolar faz parte da totalidade social e não se pode tratá-la de modo isolado. Desse ponto de vista, a pesquisa busca um conjunto amplo de relações, particularidades e detalhes que possibilitam captá-la em movimento de contradições. Analisar os determinantes da realidade da gestão escolar por meio da pesquisa em educação, utilizando-se do materialismo históricodialético permite a compreensão das condições materiais da vida social que medeiam a formação do pensamento, da linguagem e da capacidade de produzir conhecimento.

A obtenção do conhecimento empírico, com seus significados e singularidades, não pode ser feita de maneira desconectada a um determinado contexto histórico, político-social e econômico. Para tanto, assume-se nesse trabalho as categorias de análise, especialmente a categoria contradição, buscando-se evitar aspectos unilaterais e a-históricos.

Técnicas de coleta e análise de dados foram empregadas para o alcance das pistas emanadas no percurso de levantamento de dados, e, com o trato da reflexão teórico filosófica, o grupo de pesquisadores realizou 26 (vinte e seis) entrevistas semiestruturadas com diretores de escolas públicas do Distrito Federal, especificamente do ensino médio, objetivando coletar dados para análise 
das tessituras dos discursos, concepções de gestão, práticas e atitudes que possam desvelar as contradições nas condições materiais e de trabalho dos diretores escolares participantes da pesquisa. A entrevista aplicada é composta por 27 (vinte e sete) questões, divididas entre os eixos: perfil, formação, concepção de gestão, intensificação do trabalho e ética.

Sobre os dados coletados, optou-se pela aproximação do procedimento metodológico "análise de conteúdo". O ponto de partida é a mensagem verbal produzida pelos sujeitos de pesquisa a partir da entrevista semiestruturada, analisada à luz do enfoque histórico-crítico. Entende-se a linguagem em sua forma dinâmica, como uma construção real, social e como expressão histórica da existência humana. Assim, buscou-se compreender, semanticamente, o sentido que os diretores e diretoras atribuem à gestão escolar (FRANCO, 2012).

\section{Sobre as concepções de gestão escolar: propostas de educação em disputa}

A partir do período republicano, a administração pública no Brasil passou a dar maior ênfase à teoria geral da administração tecnoburocrática. Nesse contexto, a administração da educação surge de maneira conectada ao conceito de administração pública. Dessa maneira, ocorreu a importação de teorias aplicada à administração clássica e a busca de resoluções endógenas (SANDER, 2007).

O enfoque da teoria geral da administração técnico-burocrática aplicado à educação trouxe consequências para a forma de se realizar a gestão da educação: foco na eficiência e na eficácia, busca de soluções técnicas. A partir dos anos 1950, o enfoque desenvolvimentista ganha força e, então, passa a ocorrer um maior investimento e sistematização na educação, buscando a reconstrução, a produtividade. Esse momento tem como protagonista a Teoria do Capital Humano. A partir desse momento, a educação passou a ser vista como necessária para o projeto de modernização do país, para a formação da mão de obra. Nos anos 1960 a Ditadura Militar privilegiou uma forma de administração escolar voltada para a educação tecnicista, conforme as necessidades produtivas. Como a política educacional insere-se na dinâmica geral da sociedade, no capitalismo, ela fica subsumida na política econômica, buscando a preparação da mão-de-obra de acordo com a demanda empresarial e enfatizando os conceitos da Teoria do Capital Humano (SAVIANI, 2008).

Trata-se de uma teoria formulada por Theodore Schultz e difundida entre os técnicos da economia, das finanças e da educação. É uma teoria orientada 
pelos princípios da racionalidade, eficiência e produtividade, em que se busca o máximo resultado com o mínimo de dispêndio. Busca explicar os ganhos de produtividade gerados pelo fator humano na produção. Entende-se que o trabalho humano, quando qualificado por meio da educação, é um dos mais importantes meios para a ampliação da produtividade econômica, isto é, lucro do capital. Existe uma estreita relação entre a educação, a formação dos sujeitos e o desenvolvimento do país (SCHULTZ, 1973).

No entanto há críticas a esta concepção. O capital humano é compreendido no âmbito individual, desconsiderando os fatores sociais, os problemas da inserção social. A educação é reduzida ao valor econômico, equiparando o capital e o trabalho como se ambos fossem igualmente meros fatores de produção. Outro problema é que os investimentos em educação passam a ser determinados pelos critérios do investimento capitalista. Assim, a educação é reduzida a fator econômico e a escola, sua função social, é subordinada aos interesses do capital. Essa perspectiva oculta a estrutura de classes e a totalidade dinâmica das relações materiais de produção, uma vez que coloca sobre a educação a condição para melhorar a distribuição de renda (FRIGOTTO, 1993).

Observou-se, no entanto, que tais investimentos não alcançaram os resultados esperados. Na contradição da realidade educacional brasileira, os enfoques críticos e socioculturais são constituídos (SANDER, 2007). Buscou-se a construção de teorias e análises que contemplassem a realidade brasileira. Uma expressão importante das vertentes críticas é Paulo Freire - que problematizou a relação de dominação e propôs a pedagogia da libertação por meio de uma práxis educacional transformadora (FREIRE, 1967, 2005).

A partir das décadas de 1970 e 1980, o pensamento crítico educacional ganha força. A administração passa a ser compreendida como um processo político e não meramente como um processo administrativo. A partir daqui se assume que a administração de uma fábrica (pautada no modelo de apartação, colado aos interesses de uma elite dirigente, vinculada ao econômico sem olhar para o social e voltada para assegurar alguns privilégios) não poderia ser transplantada para uma escola.

Nesse movimento contraditório, a concepção de gestão educacional democrática ganha contornos relevantes, sobretudo no contexto de redemocratização do Brasil, pós ditadura militar. A compreensão dos movimentos sociais e das entidades científicas, ao lado de outros setores da sociedade, defende maior transparência do Estado e a instituição de relações democráticas com as instituições por ele organizadas.

As tensões entre concepções distintas incidem sobre o marco legal brasileiro, reflexo dessa disputa aparece na Constituição Federal de 1988. Se por um lado fica consubstanciado o princípio da gestão democrática, por outro, 
ele se restringe à educação pública. Ademais, sua regulamentação é postergada para as discussões da Lei de Diretrizes e Bases da Educação (LDB). Essa, por sua vez, desenvolve uma fraca regulamentação (PARO, 2007) ao incidir apenas na participação dos docentes na elaboração do Projeto Político e Pedagógico da escola e na progressiva autonomia didática e financeira.

A fraca regulamentação da gestão democrática das escolas públicas e dos sistemas de ensino relaciona-se com a intensa disputa entre setores públicos e privados que atuam em constante tensão na educação brasileira, sobretudo, por conta de setores empresariais não conceberem a gestão da educação como uma dimensão eminentemente política (SOUZA, 2008). Por outro lado, a Lei $\mathrm{n}^{\mathrm{o}}$ 9.394/96 (LDB) foi aprovada sob um contexto de redefinição do papel do Estado e de reforma gerencial de seu aparelho que, na gestão educacional, induziu, via políticas educacionais, à adoção de parâmetros privados nas escolas públicas em detrimento da função político-social da educação.

Sob esse árido terreno, tensões e disputas no âmbito dos sistemas estaduais e municipais de ensino, experiências de gestão democrática avançaram, dentre elas, os processos eleitorais, com participação das comunidades escolares e locais, para eleição dos diretores(as) escolares. Nos marcos contemporâneos, há uma compreensão de que apenas a eleição não dá conta da democracia na gestão, porém, é um passo significativo para o aprofundamento de relações horizontais de poder e práticas no ambiente escolar. E é nesse contexto, dinâmico e contraditório em que se insere a realidade concreta do Distrito Federal.

De 1995 a 2016, as escolas públicas do DF vivenciaram, no mínimo, três paradigmas de gestão escolar. Esse cenário de descontinuidade da política educacional é uma marca dos movimentos contraditórios e das disputas de projetos de sociedade e educação que permeiam as iniciativas governamentais no período pós-redemocratização do país. A falta de um projeto de nação que tenha a educação como um eixo estratégico do Estado, é resultante de uma institucionalidade governamental que prioriza os interesses econômicos e as demandas de reprodução e ampliação do capital em detrimento das questões sociais e suas desigualdades que acometem milhões de brasileiros e brasilienses. Nesse interregno acumularam-se experiências, ora mais democráticas, ora mais conservadoras (AIRES et al., 2016).

Fato é que a intermitência entre experiências distintas fez com que a cultura escolar no DF se assente, na atualidade, sob perspectivas diversas de gestão escolar que, muitas das vezes materializam-se sob aspectos híbridos das perspectivas vivenciadas ao longo da trajetória histórica das políticas educacionais de cada um dos governos. Na próxima seção, analisamos como esse contexto influencia na prática dos gestores escolares de instituições que ofertam o ensino médio regular no DF. 


\section{As concepções de gestão dos diretores de escolas de ensino médio do DF}

Nas entrevistas realizadas com os diretores escolares, a partir do eixo "Concepção de gestão", foram elaboradas seis perguntas referentes a estas unidades temáticas: (1) forma de provimento, (2) tomada de decisão, (3) o que não deve ter em uma gestão, (4) uma efetiva gestão. A análise dos dados, neste artigo, estrutura-se a partir dessas quatro unidades temáticas. Porém, na análise dos dados, a unidade temática o que não deve ter em uma gestão foi integrada à unidade uma efetiva gestão, isso porque, no conteúdo das repostas, verificou-se apontamentos diametralmente opostos.

A partir das perguntas propostas, constatou-se que os 26 (vinte e seis diretores ${ }^{1}$ ) abarcaram um número variável de conteúdos (subtemáticas) segundo as elaborações, conceitos, representações sociais e realidades vividas no contexto escolar do DF. Emergiram do campo de pesquisa subtemáticas variadas que foram agrupadas de acordo com a relação semântica (conteúdo expresso) e com o número de ocorrências e repetições.

Assim, elegeram-se para a análise as subtemáticas com o maior número de ocorrência entre os sujeitos, conforme mostra o quadro abaixo:

QUADRO I - OCORRÊNCIAS DE SUBUNIDADES DE CONCEPÇÃO DE GESTÃO

\begin{tabular}{|c|c|c|c|}
\hline EIXO & $\begin{array}{c}\text { UNIDADE } \\
\text { TEMÁTICA }\end{array}$ & $\begin{array}{l}\text { SUBUNIDADE TEMÁTICA } \\
\text { (emergiram do campo) }\end{array}$ & $\begin{array}{l}\text { OCORRÊNCIA ENTRE } \\
\text { OS SUJEITOS }\end{array}$ \\
\hline \multirow{10}{*}{ 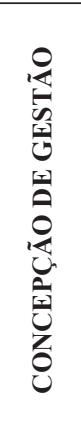 } & \multirow{3}{*}{$\begin{array}{c}\text { FORMA DE } \\
\text { PROVIMENTO }\end{array}$} & Eleição & 12 \\
\hline & & Seleção/Eleição & 09 \\
\hline & & Concurso/Seleção & 05 \\
\hline & \multirow{4}{*}{$\begin{array}{l}\text { TOMADA DE } \\
\text { DECISÃO }\end{array}$} & Decisão em níveis & 26 \\
\hline & & Decisão coletiva & 13 \\
\hline & & Autoritarismo e centralização & 11 \\
\hline & & Desrespeito & 11 \\
\hline & \multirow{3}{*}{$\begin{array}{l}\text { UMA EFETIVA } \\
\text { GESTÃO }\end{array}$} & Participação/diálogo & 12 \\
\hline & & Recursos humanos/materiais & 07 \\
\hline & & Engajamento & 07 \\
\hline
\end{tabular}

FONTE: os autores.

1 Neste trabalho, identificados como Sujeito D1, D2 etc. 


\section{Sobre a forma de provimento}

No eixo "Concepção de Gestão", a primeira pergunta feita aos entrevistados e entrevistadas foi: "Na sua opinião, qual deve ser a forma de provimento do cargo de diretor?". A partir das respostas, constatou-se que $46 \%$ entendem que a eleição, apenas, é a melhor forma de provimento; $35 \%$ entendem que a eleição deve ser combinada com um processo seletivo; e 19\% entendem que o concurso público para o cargo de diretor seria a melhor forma de provimento.

Dentre os diretores e diretoras que apontaram o processo eleitoral como a mais adequada forma de provimento, observou-se a defesa da participação da comunidade escolar no processo de escolha de seus representantes e a valorização do processo democrático como forma legítima de escolha.

Eu acredito que o processo deva ser esse mesmo, através da gestão democrática, da eleição. Acho que a comunidade que tem que escolher mesmo [...] Eu acho que tem que ter a participação de todos que fazem parte do processo escolar. [...] os professores, os alunos, os pais, eles tem que participar [...] eles que são, para mim, os que estão na dianteira pra poder ter essa prerrogativa de escolha (Sujeito D12).

Acredito que a comunidade deve eleger seus gestores por conhecerem a realidade escolar. Em primeiro momento saber das dificuldades, dos problemas [...] uma pessoa indicada, muitas vezes, só visa o retorno financeiro (Sujeito D14).

A eleição é uma forma das pessoas estarem avaliando o seu trabalho (Sujeito D18).

Eu acredito que tem que ser por eleição mesmo. Quem está na escola, os alunos, os profissionais, é quem conhece [...] tem que surgir do próprio grupo [...] tem que ser dentro da própria escola mesmo (Sujeito D26).

Ressalta-se que alguns dos entrevistados e entrevistadas que defenderam a eleição direta entendem que apenas o processo eleitoral não garante a escolha de um diretor ou diretora eficiente, capaz de sanar as exigências do cargo e de conduzir a gestão escolar de maneira eficaz e qualificada. Aponta-se a 
necessidade de garantir o processo eleitoral, mas também a formação profissional posterior à eleição.

Eu acho que tem que ter eleição, a eleição é fundamental [...] mas tem que vir outra formação [...] o ideal é que tenha a formação posterior a esse processo (Sujeito D6).

Dentre os diretores e diretoras que foram entrevistados, $35 \%$ entendem que a eleição deve ser acompanhada por um processo seletivo que garanta o mínimo possível de qualificação profissional.

a eleição [...] pode entrar um que não tem o perfil [...] um professor chamado bonzinho, que se dá bem com todo mundo [...] às vezes ele pode não ser um bom diretor [...] a eleição mesmo, porque a gente pode errar e logo ao final do mandato a gente pode consertar e colocar outro (Sujeito D1).

aqui nós tivemos um processo eleitoral [...] pessoas que tinham uma possivel capacitação, habilidade, mas eu não sei se isso aconteceu em todas as escolas [...] esse processo de seleção é justo tendo em vista que você vai colocar para a eleição, pessoas, igual agora na eleição do conselho tutelar que teve muita gente que foi reprovada (na prova) (Sujeito D2).

o cargo de diretor é um cargo em que a pessoa tem que ter uma competência técnica, administrativa e pedagógica, não pode ser eleição não (Sujeito D3).

antes eu acreditava que só a eleição bastava. Depois que você pega experiência, que você está no dia a dia, você vê que não está preparado. [...] a escola está dentro de um contexto de vulnerabilidade social, econômica, violência [...] a questão administrativa, coisa que a gente não entende, a questão da legislação [...] às vezes você vai responder uma sindicância de um processo administrativo por conta de um desconhecimento. Então é importante ter essa formação anterior à própria eleição. [...] tem que ter uma seleção, uma prova, um curso antes, 
ai depois sim, quem for classificado, quem for aprovado, participa do segundo momento que seria a eleição, para ser realmente democrático (Sujeito D8).

A seleção vai selecionar quem têm conhecimento [...] tem uma série de legislações que são muito amplas e a pessoa que entra na direção não pode estar despreparada [...] depois a eleição, porque eu penso que tem que ter o aval da comunidade [...]. Já que no Distrito Federal a gente não tem concurso para a direção [...] deveria ter concurso próprio para a função de diretor (Sujeito D17).

em função das atribuições [...] administração, de contabilidade, mexe com o financeiro, mexe com o pedagógico, mexe com toda a legislação [...] tem que ter, tem que ter seleção. [...] Uma prova, talvez não eliminatória. Mas uma prova pra mostrar o conhecimento nessas áreas de administração, de contabilidade, de financeiro, de licitação. Tem que conhecer (Sujeito D19).

Entre as diretoras e diretores que foram entrevistados, 19\% defendem o concurso público como a forma mais adequada de provimento para o cargo de direção escolar.

Eu acho que deveria ter um concurso para diretor, para o gestor [...] não precisava ser um professor de uma escola, porque eu acho que isso cria uma confusão muito grande [...] eu sou professor igual a todos os professores aqui [...] essa questão de gestão democrática atrapalha muito, porque tem o grupo dos contra e os favor [...] o grupo do contra atrapalha o andamento da escola, porque na verdade ganhou ou perdeu [...] (Sujeito D4).

Eu acho que o cargo de diretor, inclusive, ele tem que ser gestor. A pessoa tem que ter formação em gestão pública. Porque a gente lida com diversos fatores: administrativos, principalmente, lida com verba pública [...] reposição de material de expediente, reposição patrimônio [...] deveria ser um cargo mais técnico [...] Eu sempre trabalhei com meus colegas [...] de repente você assume uma função em que você continua sendo professor, porém, hierarquicamente, você passa a ser chefe deles. Tendo que tomar 
algumas decisões [...] a pressão é muito grande [...] na maior parte das vezes a gente tem que tomar medidas que não agradam (Sujeito D9).

Eu acho que deveria ser como acontece em outros estados: concurso público [...] a escola acaba tendo certa divisão, mesmo que a gente procure fazer esse tipo de trabalho de uma forma muito democrática [...] No processo de eleição, porque apoiavam outra pessoa que era candidato [...] nem sempre elas te dão aquele apoio que deveria [...] ao invés de ajudar, acabam atrapalhando porque apoiavam aquela outra pessoa (Sujeito D23).

Interessante, é que quatro dos cinco diretores que apontaram o concurso público como a forma mais adequada de provimento para o cargo de diretor, apontaram também, contraditoriamente, a participação e a valorização da comunidade escolar como elementos importantes para uma efetiva gestão escolar. Parece que tais diretores não percebem como o processo eleitoral valoriza e maximiza a possibilidade de participação e engajamento da comunidade, uma vez que esta se torna partícipe da construção dos objetivos e fins da instituição escolar.

As diversas opiniões sobre a forma de provimento ao cargo de diretor escolar evidenciam as experiências vivenciadas pela rede pública do DF. Aqui, já foram implementadas quatro leis sobre a gestão escolar, número que corresponde às gestões de diferentes governadores distritais. E, sob elas, as diferentes formas de provimento, a saber: Lei n ${ }^{\circ}$ 957/95 (governo Cristovam Buarque (PT) - 1995 a 1998) que estabeleceu a eleição direta; Lei no 247/99 (governo Joaquim Roriz (PMDB) - 1999 a 2006) que instituiu lista tríplice com indicação; Lei n ${ }^{\circ} 4.036 / 07$ (governo José Roberto Arruda (DEM) - 2007 a 2010) com processo seletivo como requisito para participação na eleição e; Lei n ${ }^{\circ} 4.751 / 12$ (Governo Agnelo Queiroz (PT) - 2011 a 2014) que vigora atualmente (2017) e instituiu a eleição direta com posterior curso de formação.

Como dissemos, a tônica de cada uma das leis revela concepções distintas e projetos em disputas. Ademais, o processo de descontinuidade das políticas, aliado à fraca regulamentação do princípio, conforma variadas compreensões na rede. Há de se considerar que as gestões identificadas com o Partido dos Trabalhadores foram mais comprometidas com a democracia nas escolas, por sua vez, as outras gestões dificultaram a gestão democrática e implementaram parâmetros tecnicistas e meritocráticos, aliados aos parâmetros gerencialistas que emergiram da reforma do estado brasileiro a partir dos anos de 1995. 
$\mathrm{Na}$ fala dos sujeitos de pesquisa, é possível perceber que ambas as concepções, em detrimento de suas diferenças, fazem parte do pensamento dos diretores escolares. Demonstrando que apenas o marco legal atual não dá conta de materializar uma cultura democrática das escolas. Nesse sentido, a formação que é oferecida aos dirigentes escolares após o processo eleitoral é fator determinante no aprofundamento dos parâmetros democráticos da gestão escolar.

Há outro elemento que faz parte de nossa análise e que se centra na percepção de que a cultura gerencialista difundida pela reforma do Estado e consubstanciada nos parâmetros da nova gestão pública que, na educação, apresenta-se por intermédio de mecanismos de avaliação externa à escola com ações de premiação e punição, de controle do trabalho docente e arbítrio de financiamento. Ou seja, medidas de responsabilização direta dos docentes e estudantes, impõem aos gestores escolares práticas centralizadoras que, muitas das vezes, acabam por compor um certo habitus que vai de encontro à gestão democrática e induz um perfil técnico do(a) diretor(a) escolar, esfumaçando o caráter eminentemente político da gestão.

\section{Análise sobre tomada de decisão}

A segunda pergunta feita aos entrevistados e entrevistadas, dentro do eixo "Concepção", foi: "Como ocorrem os processos de tomadas de decisão no espaço escolar?". A partir das respostas, constatou-se que 100\% dos gestores e gestoras conduzem os processos decisórios de acordo com os segmentos da escola e a necessidade da participação de acordo com a temática colocada em pauta - decisão em níveis. Isto significa que, a depender do assunto e da decisão que deve ser tomada, convocam-se apenas os professores, ou pais e alunos, em algum momento os funcionários e às vezes toda a comunidade escolar.

Depende da tomada de decisão... tem algumas que apenas a direção, apenas a equipe gestora toma a decisão [...] aquelas que envolvem a parte pedagógica, são chamados os professores. A gente faz reuniões periódicas, tanto com os professores quanto com o conselho escolar (Sujeito D1).

As decisões no âmbito pedagógico, elas são tomadas nas coordenações com os professores. Do que se refere à participação da nossa rotina que envolve o aluno e a comunidade, a gente reúne em assembleia todo mês de fevereiro, onde a gente determina com a comunidade as regras de convivência [...] nós temos um conselho de representantes de turma, esse 
conselho também participa das decisões no que se refere às atividades (Sujeito D6).

Questões financeiras, administrativas, elas são tomadas junto com o conselho escolar [...] decisões de cunho financeiro inicial fica entre diretor e vice e depois repassa isso ao conselho escolar [...] o conselho escolar, de certa forma, ele é sempre consultado (Sujeito D2).

A tomada de decisão é feita numa reunião da equipe gestora junto com os colegiados [...] segmento de aluno, segmento de professor, segmento de pessoal [...] dos pais [...] conselho escolar, então a gente toma as decisões juntos. [...] Só que [...] a gente tem aqui o mínimo do mínimo, porque ninguém quer participar e ninguém quer ficar tendo responsabilidade na escola. Porque não ganha nada [...] tem que fazer reuniões todo mês e ninguém quer ficar participando disso (Sujeito D4).

algumas decisões têm que ser tomadas imediatamente [...] a direção tem que tomar e tem outras que tem como você ver a opinião de cada um [...] mas na maioria das vezes a gente tenta fazer o diálogo (Sujeito D5).

a direção primeiramente se reúne com a ideias relacionadas a determinado tema [...] com as ideias pré-selecionadas nós nos reunimos com os professores na coordenação [...] A gente sempre consulta os professores, principalmente no âmbito pedagógico, porque eles que vão trabalhar. [...] O Conselho escolar participa em diversas ações não só pedagógicas como administrativas. Algumas questões de verba, de utilização de verba, requerem a aprovação do conselho escolar (Sujeito D9).

A maioria das decisões e tomada através da coordenação pedagógica [...] se for uma decisão só da direção mesmo, a gente reúne e passa para o grupo para ver se eles aceitam ou não aquilo que a gente acordou entre só a própria direção (Sujeito D26).

Ressalta-se que 50\% dos respondentes enfatizaram a importância da decisão coletiva, da participação da comunidade escolar nos processos decisórios e da legitimidade da decisão quando esta é tomada de maneira coletiva. 
Eu acredito muito na democracia, em decisões compartilhadas, democráticas, então nós incentivamos muito a participação do conselho escolar, os vários segmentos que compõem a escola [...] nós incentivamos a criação do grêmio estudantil, nós criamos também o fórum dos estudantes para subsidiar os debates, as discussões. Depois nós vamos para o fórum de deliberação que é o conselho escolar (Sujeito D8).

Seja administrativa ou pedagógica, sempre com o corpo reunido. Elabora-se uma proposta para a coordenação para levar os professores, para eleição com a comunidade. Se o assunto se estende a outras linhas, convoca-se o conselho escolar, em um processo democrático (Sujeito D15).

[...] aqui na escola é muito democrático. Primeiro a gente discute entre o grupo da direção. Depois passa para as coordenações junto com os professores. A gente discute junto com os professores, depois disso tem uma discussão junto com a comunidade, com a comunidade escolar. [...] Alguns projetos que são pensados, às vezes nem chegam a ser feitos pro conta da discussão com a comunidade [...] através da discussão, a gente vê que não é viável de acontecer (Sujeito D17).

De forma bem democrática [...] o diretor, ele está à frete do grupo, mas as decisões, elas são tomadas em conjunto com a comunidade escolar. Essa divisão de responsabilidades, eu acho que facilita bastante o trabalho [...] quando a escola fracassa, vamos dizer assim, o problema não foi o diretor! É todo o conjunto (Sujeito D23).

É importante salientar que a Lei $n^{\circ} 4.751 / 12$ trouxe em seu bojo outros mecanismos a fim de aprofundar a gestão democrática das escolas e do sistema de ensino no DF. Fruto desse processo é o regimento escolar da rede pública que organiza a educação e suas instituições (DISTRITO FEDERAL, 2015). O documento, em seu terceiro capítulo, versa sobre a gestão democrática das escolas e discorre sobre a participação e os processos de tomada de decisões no âmbito das instituições. Além da direção e da vice-direção, estabelece os órgãos colegiados: a) Assembleia Geral Escolar, b) Conselho Escolar, c) Conselho de Classe e d) Grêmio Estudantil.

O conjunto desses órgãos colegiados contribui para a prática democrática no cotidiano das escolas e influenciam diretamente, como visto, as falas dos 
dirigentes. Outro aspecto, não menos importante, são os cursos de formação para esses sujeitos, assim como a formação continuada oferecida para o conjunto da rede, contribuem para atribuição de sentidos que é dada à participação no âmbito das instituições.

Por fim, cabe salientar os aspectos contraditórios entre a apreciação crítica que parte dos dirigentes fazem em relação à eleição - defendendo o processo seletivo e o concurso público, de caráter mais técnico -, e a ampla aceitação dos mecanismos de participação internos à escola. Em nossa análise entendemos que a pressão exercida pelas políticas educacionais de caráter regulador-burocrático exerce dois movimentos desiguais, porém combinados. Se, por um lado, induzem à adoção de procedimentos gerencialistas, o que leva aos dirigentes a defenderem critérios técnicos de escolha para o cargo, por outro lado, a responsabilização exercida sob a figura do diretor, os leva a tentar socializar as decisões e dividir as tarefas a fim de obter apoio interno para enfrentar as pressões externas.

\section{Análise sobre os elementos de uma efetiva gestão}

Por fim, a última pergunta proposta para o eixo "Concepção" foi: "Pela sua compreensão e experiência, como se constitui uma efetiva gestão escolar? ”. Entre os elementos mais apontados como necessários à efetiva gestão estão: a participação e o diálogo (46\%), os recursos humanos e materiais $(26 \%)$ e o engajamento profissional (26\%).

Quanto à participação:

[...] a gente imagina que ela tem que ser efetiva com a participação de todos os segmentos que compõem a comunidade escolar [...] professores, auxiliares, pais e alunos. A gestão deveria fluir com esses elementos casados e funcionando numa engrenagem que pudesse dar sustentação política e de gestão [...] a efetiva gestão democrática é você ter a vontade de fazer, você consultar aqueles que querem participar do processo e você abrir canais para que outros se aproximem desse processo (Sujeito D6).

[...] democratizar as decisões. Reunir sempre [...] acho que as decisões serem tratadas de forma bem democrática [...] cada um sabendo do seu papel, sabendo resolver tudo (Sujeito D8).

[...] a gente trabalha em equipe. A equipe é necessária! [...] se você não se envolve com o trabalho todos os dias, esse trabalho não acontece. Os 
projetos não vão para frente. Tem que ter o envolvimento de todo mundo na escola (Sujeito D17).

Eu acho que a maior presença das familias, da comunidade [...] eles não sabem o poder que têm. Porque o conselho escolar tem um poder muito grande [...] é formado pelo lado da escola e do outro lado tem o segmento aluno, tem o segmento pai. E a comunidade não vê o poder que ela tem por meio do Conselho escolar [...] Eu acho que a presença da comunidade é fundamental (Sujeito D22).

As falas dos diretores coadunam com aquelas referentes aos processos de tomada de decisão e reforçam a análise de que a obtenção de sustentação política da equipe gestora passa, necessariamente, pelo incentivo à participação das comunidades interna e local. Demonstra, assim, a importância de elementos complementares para além da eleição ao cargo a fim de construir uma cultura democrática nas instituições. Não por acaso, as críticas levantadas em relação à gestão dos recursos materiais e humanos são um nó do ponto de vista da efetivação da gestão democrática, sobretudo em seus aspectos pedagógicos.

Quanto aos recursos materiais e humanos:

[...] para o bom funcionamento da escola, no que se refere à sua perspectiva material, de estrutura, de proposta pedagógica, os projetos pedagógicos, você precisa canalizar recursos para que eles possam ocorrer da melhor maneira possivel [...] distribuir os recursos que nós temos tanto para parte pedagógica quanto para a administrativa (Sujeito D6).

[...] o diretor e o vice têm as atribuições financeiras [...] são tão complicadas e tão burocráticas que acabam tomando o tempo [..] se você não tiver uma boa equipe de supervisor pedagógico e de coordenadores pedagógicos, o centro, que é a parte pedagógica, fica em segundo plano (Sujeito D2).

[...] deveríamos ter o diretor e o diretor pedagógico [...] nossa escola é grande [...] porque acaba sobrecarregando [...] pela parte financeira, então ele acaba que uma hora tem que deixar o pedagógico à parte para cuidar da parte financeira, ou vice-versa (Sujeito D7). 
[...] em termos de recursos humanos... Não contempla! Isso é uma briga [...] As escolas são muito grandes. A quantidade de aluno é muito grande e você às vezes acaba sobrecarregando parte da equipe [...] se um adoece [...] Eu acho que falta recursos humanos na rede (Sujeito D26).

Vale registrar que a reforma do Estado brasileiro trouxe em seu bojo uma concepção de desconcentração dos sistemas de ensino. Com o discurso aparente de descentralização dos recursos e de autonomia financeira das escolas, a essência da política de financiamento direto das escolas, intensificou o trabalho do diretor escolar por intermédio de exigências para criação de unidades executoras (UEX) - empresas com CNPJ, sem fins lucrativos - que, no DF, obrigatoriamente, deve ser presidida pelo diretor escolar para recebimento de recursos oriundo do Programa Dinheiro Direto na Escola (PDDE), de âmbito federal, e do Programa de Descentralização Administrativa e Financeira (PDAF), de âmbito local.

É possível perceber nas falas dos dirigentes que há um processo burocrático que acaba por subsumir questões político-pedagógicas que são próprias da função. Não obstante, é necessário compreender que as questões administrativas fazem parte do trabalho docente, em especial, da função política exercida pelo cargo, porém, é preciso desmistificar

a noção de administração do senso comum, [que] deixa de captar o que há de administrativo no processo pedagógico (ao limitar a administração às normas e aos procedimentos relativos à organização e ao funcionamento da escola), acaba por valorizar aquele que é o responsável direto pelo controle das pessoas que devem cumprir essas normas e realizar esses procedimentos: o diretor escolar (PARO, 2015, p. 19-20).

Nesse sentido, as exigências diretas, como a imposição à presidência do diretor nas UEXS, servem ao governo como um instrumento de mais responsabilização e intensificação do trabalho docente do dirigente escolar. Exemplos são vastos como, por exemplo, o não recebimento de recursos caso haja algum problema no processo de prestação de contas, que é de responsabilidade direta da presidência. Veja, é óbvio que a administração dos recursos deve seguir as normas que regem sua utilização, o problema principal é responsabilizar somente o diretor, sem dar espaço para que outras pessoas participem do processo. Isso materializa-se em uma estratégia para velar a escassez de recursos e dar ênfase na administração de migalhas. 
Não por acaso, de forma recorrente, aparecem proposições, como visto nas respostas, de criação de cargos de diretor pedagógico e diretor administrativo/ financeiro, fragmentando a perspectiva do gestor escolar como uma função que reúne questões administrativas que precisam estar a serviço do pedagógico e não ao contrário. Assim, compreendendo o administrativo como uma mediação para atender a determinados fins, e que a função social da escola é educar, nada mais administrativo que as questões pedagógicas para atender as finalidades. "É, portanto, o pedagógico que dá a razão de ser ao administrativo, senão este se reduz a mera burocratização, fazendo-se fim em si mesmo e negando os fins educativos a que deve servir" (PARO, 2015, p. 25).

As políticas de responsabilização e intensificação do trabalho do diretor acabam por criar uma cultura que despotencializa a participação de outros atores, sejam eles da comunidade escolar ou local. Assim, também faz parte da concepção de gestão democrática o estímulo para o engajamento social e profissional.

Quanto ao engajamento profissional:

[...] que tenha a participação de todos os segmentos da escola (Conselho Escolar). Você não pode pegar lá... a pessoa tem que ser espontânea, tem que ser uma pessoa que queira fazer realmente parte desse trabalho [...] todo mundo aqui engajado, é claro os professores têm que querer [...] na verdade é obrigado a trabalhar, mas tem gente que não trabalha (Sujeito D4).

eu preciso que todos os elementos estejam encaixados, com todo mundo trabalhando [...] com responsabilidade, assumindo seus compromissos, assumindo suas atribuições (Sujeito D9).

Compromisso. Compromisso não é só da equipe gestora não. $O$ compromisso é de todos, de todos! Dos professores, começando desde lá... da moça que está limpando a mesa, da porteira [...] esse compromisso de todos envolve a escola e as outras áreas da Secretaria, da Regional de Ensino. Todas as instâncias. Se houver o compromisso de todos, eu não preciso de mais nada (Sujeito D11).

Os respondentes demonstram o entendimento de que o engajamento profissional se confunde com participação e compromisso. A rigor estão 
imbuídos nas funções docentes elementos que caminham para participação como, por exemplo, na discussão e elaboração do projeto político-pedagógico. Nesse sentido, a conjunção dessas categorias compõe a dimensão política do trabalho docente. Ou seja, estão corretos os dirigentes que fazem reclamar o compromisso dos professores. Por outro lado, vale registrar que, assim como há intensificação das funções do diretor escolar, as mesmas políticas educacionais de caráter tecnoburocrático também intensificam o trabalho dos professores e que, muitas das vezes, sobrepujam sua participação nas instâncias colegiadas das instituições.

Há de se considerar que a participação da comunidade escolar e local precisam ser incentivadas, sobretudo, a partir de mecanismos de democratização que horizontalize a tomada de decisão e os espaços de poder. Além disso, considerar que os espaços colegiados da escola são vias de conscientização e reflexão crítica na perspectiva da práxis emancipadora. Como aponta Freire (1980, p. 26):

A conscientização implica, pois, que ultrapassemos a esfera espontânea de apreensão da realidade, para chegarmos a uma esfera crítica na qual a realidade se dá como objeto cognoscível e na qual o homem assume uma posição epistemológica. A conscientização é, nesse sentido, um teste de realidade. Quanto mais conscientização, mais se "des-vela" a realidade, mais se penetra na essência fenomênica do objeto, frente ao qual nos encontramos para analisá-lo. Por esta mesma razão, a conscientização não consiste em "estar frente à realidade" assumindo uma posição falsamente intelectual. A conscientização não pode existir fora da práxis, ou melhor, sem o ato ação-reflexão. Esta unidade dialética constitui, de maneira permanente, o modo de ser ou transformar o mundo que caracteriza o homem.

De tal forma que é necessário reafirmar a gestão democrática e seus elementos constitutivos como pilares do trabalho docente de direção escolar, assim como as iniciativas que emergem dessa concepção, fortalecendo a unicidade das instituições a partir dos sujeitos históricos e sociais que as constituem. Por fim, essa ideia também nos serve para pensar e agir de modo que as políticas educacionais de cariz tecnicistas e burocráticas possam ser dissuadidas em favor de práticas crítico-reflexivas emancipatórias. 


\section{Considerações finais}

O artigo discutiu as concepções de gestão dos diretores escolares do ensino médio no Distrito Federal e buscou analisá-las sob o prisma do materialismo histórico-dialético, compreendendo que os fenômenos educacionais e suas políticas não podem ser analisados de forma isolada da realidade concreta que se apresenta na totalidade social.

Nesse sentido, analisamos os principais matizes que dão forma a concepções distintas de sociedade, Estado e educação e como essas conformam práticas de gestão educacional e escolar. Entendemos que o avanço do debate e das formulações em torno da temática alcança marcos significativos a partir do processo de redemocratização brasileira com a inscrição do princípio da gestão democrática da educação na Constituição Federal de 1988 e, posteriormente, com sua (fraca) regulamentação na Lei de Diretrizes e Bases da Educação Nacional.

Mesmo com a inscrição do princípio nos marcos legais, não se esgotam os projetos em disputa e as políticas educacionais implementadas em âmbito governamental, influenciadas pela reforma do Estado brasileiro e compromissadas com os parâmetros do capital, que vão na contramão da democratização das escolas e incidem na formação dos sentidos atribuídos pelos gestores ao papel da gestão nas instituições.

Não por acaso verificam-se distintas concepções, ora mais democráticas, ora mais conservadoras, e que convivem, contraditoriamente, na cultura escolar. Essas determinam as opiniões e a reflexão dos gestores acerca da forma de provimento ao cargo de direção, os processos de tomada de decisão e os elementos que compõe a gestão escolar. Por sua vez, a realidade concreta, caminha para a ascensão de certo hibridismo de opiniões e práticas. Se, por um lado, os gestores são levados a tarefas burocratizadas de cunho centralizadoras; por outro, a pressão externa exercida via política de responsabilização, contraditoriamente, faz com que os diretores busquem sustentação política das comunidades escolares e local para seu trabalho.

Há uma janela de oportunidades que vai depender da forma e do conteúdo de como são tratadas as questões de administração no espaço escolar. Ao tratá-las articuladas com a função social da educação e seus determinantes ético-políticos, as questões administrativas estarão subsumidas às questões pedagógicas e de formação crítico-emancipadoras. Nessa toada a participação, o engajamento profissional e o compromisso das comunidades são elementos fundantes da gestão democrática. São eles também os mecanismos que podem dissuadir as pressões das políticas tecnicistas e burocráticas, forjando e fortalecendo espaços colegiados de reflexão crítica a partir do compromisso ético-político dos docentes, estudantes, pais e comunidades locais. 


\section{REFERÊNCIAS}

AIRES, C. J. et al. A gestão democrática no Distrito Federal na perspectiva histórico-legal: em busca da efetivação entre avanços, recuos e desafios. In: CUNHA, C. da; SOUSA, J. V. de; SILVA, M. A. da (orgs.) Investigação em política e gestão da educação: métodos, temas e olhares. 1. ed. Belo Horizonte: Fino Traço, 2016.

BALL, S. J. Educação Global S.A.: novas redes políticas e o imaginário neoliberal. Tradução de Janete Bridon. Ponta Grossa: UEPG, 2014.

DISTRITO FEDERAL. Lei $n^{\circ}$ 4.751, de 7 de fevereiro de 2012.

DISTRITO FEDERAL. Secretaria de Estado de Educação (SEE/DF). Regimento Escolar da Rede Pública de Ensino do Distrito Federal. 6. edição. Brasília, 2015.

FIORI, J. L.; TAVARES, M. C. Poder e dinheiro: por uma economia política da globalização. 5. edição. Petrópolis: Editora Vozes, 1998.

FRANCO, M. L. P. B. Análise de conteúdo. Brasília: Liber Livro, 2012.

FREIRE, P. Educação como prática da liberdade. Rio de Janeiro: Paz e Terra, 1967.

FREIRE, P. Conscientização, teoria e prática da libertação: uma introdução ao pensamento de Paulo Freire. 3. edição. São Paulo: Moraes, 1980.

FREIRE, P. Pedagogia do Oprimido. São Paulo. Ed. Paz e Terra, 2005.

FRIGOTTO, G. A produtividade da escola improdutiva: um (re)exame das relações entre educação e estrutura econômico-social capitalista. 4. edição. São Paulo: Cortez, 1993.

MARTINS, A. S.; NEVES, L. M.V. Educação básica: tragédia anunciada? São Paulo: Xamã, 2015.

MENDES, C. S. Três paradigmas de gestão escolar em questão: o Distrito Federal entre 1995 e 2010. In: SILVA, M. A.; CUNHA, C. (Orgs.) Educação básica: políticas avanços e pendências. Campinas: Editora Autores Associados, 2014.

PARO, V. H. O princípio da gestão escolar democrática na LDB. In: OLIVEIRA, R. P. de; ADRIÃO, T. Gestão, financiamento e direito à Educação: análise da Constituição Federal e da LDB. 3. edição. São Paulo: Xamã, 2007. p. 73-81.

PARO, V. H. Diretor escolar: educador ou gerente. São Paulo: Cortez, 2015.

SANDER, B. Administração da Educação no Brasil. Brasília: Líber Livro, 2007.

SAVIANI, D. História das ideias pedagógicas no brasil. 2. edição. Campinas: Autores Associados, 2008.

SCHULTZ, T. W. Capital humano: investimentos em educação e pesquisa. Rio de Janeiro: Zahar, 1973. 
SOUZA, Â. R. de. A produção do conhecimento e o ensino da gestão educacional no Brasil. Revista Brasileira de Política e Administração da Educação, ANPAE, [S. 1.], v. 24, n. 1, mar. 2011. DOI: http://dx.doi.org/10.21573/vol24n12008.19238. Disponível em: $<$ http://seer.ufrgs.br/index.php/rbpae/article/view/19238>. Acesso em: 15 fev. 2018.

Texto recebido em 18 de janeiro de 2018. Texto aprovado em 30 de janeiro de 2018. 